Original Article

\title{
STD rapid assessment in Rwandan refugee camps in Tanzania
}

Philippe Mayaud, Wences Msuya, James Todd, Godfrey Kaatano, Beryl West, Genevieve Begkoyian, Heiner Grosskurth, David Mabey

\author{
African Medical \\ Research Foundation \\ (AMREF), Mwanza, \\ Tanzania \\ P Mayaud \\ W Msuya \\ J Todd \\ H Grosskurth \\ London School of \\ Hygiene and Tropical \\ Medicine, UK \\ $P$ Mayaud \\ J Todd \\ B West \\ H Grosskurth \\ D Mabey \\ National Institute for \\ Medical Research \\ (NIMR), Mwanza \\ Tanzania \\ G Kaatano \\ United Nations High \\ Commission for \\ Refugees (UNHCR), \\ Ngara, Tanzania \\ G Begkoyian \\ Address correspondence to: \\ Prof David Mabey, \\ Sciences, London School of \\ Sciences, London Sch
Hygiene and Tropical \\ Hygiene and Tropical \\ Medicine, Keppel Street,
London WC1E 7HT, UK. \\ Accepted for publication \\ 4 September 1996
}

Objective: To obtain baseline information on sexually transmitted diseases (STDs) in the Rwandan refugees camps in Tanzania, prior to establishment of STD services.

Setting: The largest camps of Rwandan refugees in the Ngara District of Tanzania (estimated population 300 000). The study was carried out in 8 days in August 1994.

Subjects and methods: A rapid assessment technique was used to measure STD prevalences among: (i) 100 antenatal clinic attenders (ANC); (ii) 239 men from outpatient clinics (OPD); and (iii) 289 men from the community. Interviews (by questionnaire) and genital examination were performed for all participants; sampling for females included genital swabs for the the diagnosis of Neisseria gonorrhoeae (NG), Candida albicans (CA), Trichomonas vaginalis (TV), bacterial vaginosis (BV) and a blood sample for syphilis serology. Men provided urine samples which were screened for leucocytes using the leucocyte esterase (LE) dipstick; urethral swabs for Gram stain were taken from men with a reactive LE test and from those with symptoms or signs of urethritis. OPD males provided a blood sample for syphilis serology.

Results: All groups reported frequent experience with STDs and engaging in risky sexual behaviour prior to the survey. During the establishment of the camps, sexual activity was reportedly low. Over $50 \%$ of ANC attenders were infected with agents causing vaginitis (TV/BV/CA) and 3\% were infected with NG. The prevalence of active syphilis was $4 \%$. In the male outpatients, the prevalence of urethritis was $2 \cdot 6 \%$ and of serological syphilis was $6 \cdot 1 \%$. Among males in the community, the prevalence of urethritis was $2.9 \%$ (the majority being asymptomatic infections). We noted frequent over-reporting of STD symptoms, unconfirmed clinically or biologically.

Conclusions: STD case detection and management should be improved by training health workers in using the WHO syndromic approach, and through IEC campaigns encouraging attendance at clinics. Rapid epidemiological methods provide quick and useful information at low cost in refugee camps.

(Genitourin Med 1997;73:33-38)

Keywords: refugee; Rwanda; Tanzania; STD; HIV

\section{Introduction}

Following the dramatic events which took place in Rwanda from April to June 1994, over 300000 people crossed the border with Tanzania within a few weeks and were confined in two major camps in the Ngara District, Northwest Tanzania. This situation has produced conditions which could enhance the transmission of HIV: family and social disintegration, dependency and poverty. The commercial and other interactions between the refugees and the local Tanzanian communities, also put the populations living in and around these camps at risk for the transmission of sexually transmitted diseases (STDs), which enhance the risk of HIV transmission. ${ }^{1-3}$

In earlier studies in Rwanda, the HIV prevalence was measured and was between $5 \%$ (in rural areas) and 35\% (in urban areas, for example, Kigali). ${ }^{4}$ In contrast, HIV prevalence in the Ngara District ranges from 3\% in remote rural areas to $8 \%$ in settlements along the main highways. ${ }^{5}$ Intervention strategies against HIV in Africa focus primarily on the sexual transmission of the virus; we have recently demonstrated that early detection and effective treatment of STDs decreased HIV transmission in the neighbouring Mwanza Region of Tanzania. ${ }^{6}$
During the initial phase of establishment of the camps, there was a paucity of information concerning STDs. Firstly, as usual in emergency situations, priority was given to data collection and interventions in the areas of shelter, sanitation and nutrition. Moreover, clinic records revealed only a very low rate of clinic attendance for STDs: for example in the months of June and July 94, only 50 weekly cases of STDs were recorded among 20000 adult patients attending outpatient departments. ${ }^{7}$ The purpose of this study was to assess STD prevalences, disease presentation and symptom reporting by patients, in order to target STD service delivery more efficiently.

In acute situations such as refugee crises, epidemiological techniques in the form of rapid assessment surveys have been recommended and can be used to prioritise health responses quickly. ${ }^{8}$ Cluster sampling techniques used to determine vaccine coverage of a population have successfully been developed for rapid epidemiological assessment and for disease estimates in refugee camps. ${ }^{8}$ The technique is simple and easy to perform at a relatively low cost and results are quickly made available for decision-making. 
STD rapid assessment methodology has been evaluated by WHO in Senegal and Uganda $^{9}$; the conclusion was that gold standard laboratory diagnostic tests were necessary for STD screening. However, since such tests are not yet available in most developing countries, least of all in emergency situations, we felt a further evaluation to be justified. The findings were used to help UNHCR and other NGOs (i) plan resource allocation (drugs, personnel); (ii) adopt an appropriate strategy for STD case finding; (iii) assist in the design of STD training; and (iv) measure the impact of the programme through a baseline and a follow up survey. We report here the findings of the baseline rapid STD assessment survey conducted in August 1994. A future survey will be conducted in 1995 after the implementation of a comprehensive STD/HIV control programme in the camps.

\section{Methodology \\ Study population and design}

The rapid assessment of STDs consisted of three interlinked studies undertaken during one week in August 1994. In an antenatal clinic (ANC) study, 100 women were systematically enrolled (one in every five women) from the only operational ANC in the camps at the time of the study. In a second study in the six operational outpatients (OPD) in the camps, 40 men were randomly selected for enrolment from each OPD.

The third study involved men in the community. In order to ensure that a representative sample was obtained, a multi-stage random cluster sampling frame was used. Firstly, the two camps were divided in "zones", using existing maps with the roads as grids. The number of "zones" to be selected in each camp was proportional to the population of the camps (4 zones in the camp of 200000 and 2 zones in the other camp of 100000 ). Within each camp the "zones" had an equal probability of inclusion. Within each zone, one cluster was randomly selected being one of the existing administrative "sectors".

Within each selected cluster a suitable working site for examination was selected. Each of the four field workers picked a direction based on the random throw of a pencil, walked for 50 to 100 metres and entered the fourth tent or dwelling on their right side to begin the household survey. Seven households were included by each field worker, turning left after each completed household. All men aged 15-54 years living in those households were eligible for the survey. The household was defined as a self-contained family unit, and in certain situations there was more than one tent or dwelling. The number and definition of household members was ascertained by the head of family unit. A total of 168 households were visited.

\section{Clinical methods}

All subjects were interviewed in Kinyarwanda, using a structured questionnaire. Information collected was on socio-demographic character- istics, obstetric and contraception history (for females), past history of STDs, reported symptoms of genital discharge syndrome (GDS) and genital ulcer syndrome (GUS), and on sexual behaviour.

At the antenatal clinic a full physical and gynaecological examination was performed for all participants, during which vaginal swabs were collected for immediate wet preparation and gram staining. Cervical swabs were collected for culture of Neisseria gonorrhoeae (NG) on a modified Thayer-Martin (MTM) agar and Gram stain. Finally, all patients submitted a blood sample for syphilis serology.

All men in both the OPD and community studies were examined, including their genital area. They were asked to provide a first void urine sample which was screened for the pres- के ence of pus cells using a leucocyte esterase dip- $\vec{\circ}$ stick (LE test) (Nephur test + Leuco, Boehringer-Mannheim, UK). Subjects with a reactive LE test or patients with symptoms or $\stackrel{0}{=}$ signs were further sampled with a urethral $\omega$ swab for a Gram stained smear. Blood samples for syphilis serology were collected from men $\underset{\omega}{\omega}$ attending OPD clinics only.

All patients found to have a urethral dis- $\rightarrow$ charge, or with a reactive LE test were treated TD syndromically. Results of syphilis serology were communicated privately two weeks after the consultation and treatment was provided at that time.

STD indicators used were similar to those described in the WHO studies: (1) past or present symptoms of selected STDs, as reported by individuals; (2) signs, as noted by the clinician during examination; (3) reactive LE test (a simple bedside test which could be used as a surrogate marker of urethritis). Each indicator was validated against a confirmatory laboratory test indicating the presence or absence of STD.

\section{Laboratory methods}

Wet preparations were immediately examined for the presence of Trichomonas vaginalis (TV) or Candida albicans (CA). Vaginal smears were gram-stained for the presence of "clue cells" 윽 more than $20 \%$ of epithelial cells being "clue cells" was taken as evidence of bacterial vaginosis (BV). ${ }^{10}$

MTM plates were placed in a candle-extinc- N tion jar until the end of the clinic and trans- N ported to the laboratory. They were incubated for 48 hours in a $5-10 \% \mathrm{CO}_{2}$ atmosphere and temperature of $33-35^{\circ} \mathrm{C}$. Unfortunately because of the difficult logistic conditions prevailing, it was difficult to isolate NG. Thus the diagnosis of NG for women was based on the presence of gram-negative intracellular diplococci on the cervical smear. For male patients, $\frac{2}{\sigma}$ gonorrhoea was diagnosed when Gram negative intracellular diplococci were present in a urethral smear. The presence of more than 5 pus cells per high power field on a urethral smear, in the absence of intracellular gram negative diplococci, was taken as evidence of non-gonococcal urethritis (NGU). For logistic reasons, it was unfortunately not possible to test for Chlamydia trachomatis infection in this study. 
Table 1 Characteristics of studied populations in Rwandan refugee camps in Tanzania

\begin{tabular}{|c|c|c|c|}
\hline Characteristics & $\begin{array}{l}\text { Antenatal } \\
(N=100)\end{array}$ & $\begin{array}{l}\text { Male OPD } \\
(N=239)\end{array}$ & $\begin{array}{l}\text { Male community } \\
(N=289)\end{array}$ \\
\hline $\begin{array}{l}\text { Demographic } \\
\text { Mean Age (SD) }\end{array}$ & $27(6)$ & $30(8)$ & $30(10)$ \\
\hline $\begin{array}{l}\text { Marital status: } \\
\text { Monogamous } \\
\text { Polygamous } \\
\text { Div/Seperated } \\
\text { Widowed } \\
\text { Single }\end{array}$ & $\begin{array}{r}74 \\
18 \\
1 \\
7 \\
0\end{array}$ & $\begin{aligned} 148(62 \%) \\
4(1 \cdot 7) \\
5(2 \cdot 1) \\
11(4 \cdot 6) \\
71(30)\end{aligned}$ & $\begin{aligned} & 151(52 \%) \\
& 7(2 \cdot 5) \\
& 13(4 \cdot 5) \\
& 4(1 \cdot 4) \\
& 114(40)\end{aligned}$ \\
\hline $\begin{array}{l}\text { Sexual behaviour: } \\
\text { No. partners last year } \\
\text { None } \\
1 \\
\text { More than } 1\end{array}$ & $\begin{array}{r}0 \\
98 \\
2\end{array}$ & $\begin{array}{r}65(27) \\
149(62) \\
25(10)\end{array}$ & $\begin{array}{r}77(27) \\
124(43) \\
88(30)\end{array}$ \\
\hline $\begin{array}{l}\text { No. partners last } 3 \text { months: } \\
\text { None } \\
1 \\
\text { More than } 1 \\
\text { Contact with CSW } \\
\text { Ever used condoms }\end{array}$ & $\begin{array}{r}11 \\
88 \\
1 \\
-1\end{array}$ & $\begin{array}{r}89(37) \\
142(59) \\
8(3 \cdot 3) \\
11(4 \cdot 6) \\
20(8 \cdot 4)\end{array}$ & $\begin{array}{r}108(37) \\
144(50) \\
37(13) \\
30(10) \\
31(11)\end{array}$ \\
\hline $\begin{array}{l}\text { History of STDs } \\
\text { Reported GDS ever } \\
\text { Reported GDS last } 3 \text { months } \\
\text { Reported GUS ever } \\
\text { Reported GUS last } 3 \text { months }\end{array}$ & $\frac{12}{9}$ & $\begin{array}{r}32(13) \\
6(2 \cdot 5) \\
18(7 \cdot 5) \\
6(2 \cdot 5)\end{array}$ & $\begin{array}{l}39(13) \\
8(2 \cdot 8) \\
30(10) \\
10(3 \cdot 5)\end{array}$ \\
\hline
\end{tabular}

GDS = genital discharge syndrome.

GUS = genital ulcer syndrome

Antibodies to Treponema pallidum were detected using a haemagglutination assay (TPHA, Fujirebio, Tokyo, Japan) and the Rapid Plasma Reagin test (RPR, VD 25Murex Diagnostics, Cambridge, UK). Sera reactive with both tests were considered as untreated or recently treated treponemal infection, which we shall call "active" syphilis in the text; non-venereal treponematoses have not been reported in Tanzania or Rwanda since the 1960s.

\section{Statistical methods}

The three studies in the rapid assessment were analysed separately. Data were entered using Dbase IV and frequencies were obtained using EPI-INFO.

\section{Results}

Enrolment

One hundred ANC attenders were enrolled and interviewed. All women consented to a full genital examination and allowed blood samples to be taken. A total of 239 male OPD patients were recruited and interviewed, 9 refused the examination and 6 refused to give a

Table 2 Prevalence of STD and RTI pathogens among Rwandan refugees in Tanzania

\begin{tabular}{|c|c|c|c|}
\hline Pathogens & $\begin{array}{l}\text { Ante natal } \\
(N=100)\end{array}$ & $\begin{array}{l}\text { Male OPD } \\
(N=233)\end{array}$ & $\begin{array}{l}\text { Male community } \\
(N=272)\end{array}$ \\
\hline \multicolumn{4}{|l|}{$\begin{array}{l}\text { Urine specimens } \\
\text { LED test: }\end{array}$} \\
\hline $\begin{array}{l}1+ \\
2++ \\
3+++\end{array}$ & - & $\begin{array}{r}49 \\
11 \\
3\end{array}$ & $\begin{array}{r}42 \\
12 \\
0\end{array}$ \\
\hline \multicolumn{3}{|l|}{ Genital specimens: } & $4(1 \cdot 5 \%)$ \\
\hline $\begin{array}{l}\text { NGU } \\
\text { C. albicans (CA) }\end{array}$ & 27 & ND $^{3(1 \cdot 3 \%)}$ & $\begin{array}{l}4(1 \cdot 5 \%) \\
\text { ND }\end{array}$ \\
\hline T. vaginalis (RV) & 31 & ND & ND \\
\hline BV (clue cells) & 16 & ND & ND \\
\hline $\begin{array}{l}\text { Any RTI } \\
\text { (NG/TV/BV/CA) }\end{array}$ & 60 & - & - \\
\hline \multicolumn{4}{|l|}{ Serology: } \\
\hline TPHA + ve/RPR + ve & 2 & $11 / 179(6 \cdot 1 \%)^{\star}$ & ND \\
\hline TPHA + ve/RPR - ve & 4 & 3 & \\
\hline TPHA - ve/RPR + ve & 2 & 6 & \\
\hline TPHA - ve/RPR - ve & 92 & 159 & \\
\hline
\end{tabular}

^One OPD did not permit blood samples to be taken. blood sample. In one OPD blood sampling was not permitted. In the community, 312 men were eligible, 289 (93\%) were interviewed, 265 (85\%) examined.

\section{Self-reported behaviour and STD symptoms}

The main characteristics of the studied populations are presented in table 1. Female ANC attenders were younger than males from OPD clinics or the community. A high proportion of men were unmarried in the community $(45 \cdot 3 \%)$, but few widowers were recorded.

Reported sexual behaviour data show that very few women admitted to multiple sexual partners, and only one had ever used a condom. High risk sexual behaviour was frequently reported by men during the past year (including the period prior to the troubles): multiple sexual partnerships were frequent $(30.4 \%$ of community men and $10.5 \%$ of the OPD patients). Contact with commercial sex workers (CSWs) was also frequently reported $(10.4 \%$ and $4.6 \%$ respectively), but reported lifetime condom use was similarly low in both groups (8 to $11 \%$ ).

During the period covering the war and exodus (the past three months), however, a high proportion of men in both groups (37\%) denied sexual relationships, even among married men. A small fraction of the community men, despite the difficult living conditions in the camps, admitted to multiple sexual relationships $(10 \%$ in the community and $3 \%$ in OPD males)

Twelve percent of women and $13 \%$ of men reported a lifetime episode of genital discharge syndrome (GDS) and $9 \%$ of women and $10 \%$ of men reported a lifetime experience of genital ulcer syndrome (GUS). $2 \cdot 8 \%$ and $3 \cdot 5 \%$ of men experienced GDS or GUS respectively in the past 3 months (the question was not asked of women).

Women reported frequent experience of adverse outcomes of pregnancy: of 82 multigravid women, $16(20 \%)$ had previously experienced spontaneous abortions, $8(10 \%)$ had experienced stillbirths and $3 / 80(4 \%)$ of the women who had delivered at least once, reported experience with ophthalmia neonatorum in their baby.

\section{Prevalence of STDs and reproductive tract} infections (RTIs)

The prevalence of laboratory confirmed infections is shown in table 2 . Overall $60 \%$ of ANC attenders were found to have a reproductive tract infection (RTI), if candidiasis and bacterial vaginosis (BV) are included. However, gonorrhoea was diagnosed in only $3 \%$ of women.

Ninety eight percent of men were uncircumcised. A poor standard of genital hygiene was observed in both men and women. Among men attending OPD clinics, 233 $(97 \%)$ submitted a urine sample and $63(27 \%)$ had a reactive LE test; 3 further men were eligible for swabbing because of symptoms and a total of 65 men were eventually sampled $(98 \%)$. Of those, 3 were positive for NG ( $4.6 \%)$, and 3 had non-gonococcal urethritis (NGU). Thus the minimum prevalence of 
urethritis (NG and NGU) was $2 \cdot 6 \%(6 / 233)$. None of these six subjects complained of dysuria or urethral discharge.

In the community group, of 289 men interviewed, a urine sample was collected from 272,54 of whom were LE positive $(20 \%)$. All 63 eligible men were swabbed. Four individuals had gonorrhoea (6.3\%), and 4 subjects had NGU (6.3\%). Thus the minimum prevalence of urethritis (NG and NGU) was $2.9 \%$ $(8 / 272)$. One of the men with gonorrhoea complained of dysuria and one of discharge; two of those with NGU complained of dysuria.

The prevalence of active syphilis was $2 \%$ in antenatal clinic attenders, and $6 \%$ in male outpatients tested.

\section{Current STD symptoms and signs}

The prevalence of symptoms and signs of STDs are shown in table 3. Symptoms relating to genital tract infections were reported by $63 \%$ of women. On examination an abnormal vaginal discharge was noted in $51 \%, 60 \%$ of whom had actually reported a symptom related to GDS (vaginal discharge, genital itching, lower abdominal pain, dysuria, or dyspareunia). No genital ulcers or genital warts were noted, although 6 women complained of "genital erosions". Lower abdominal pain (LAP) was reported by 56 women, but pelvic inflammatory disease (PID) was only diagnosed in one. The overall genital hygiene of these women was very poor due to the scarcity of water, possibly resulting in an exacerbation of genital symptoms and signs.

Community men, when prompted, reported more frequent STD-related symptoms than males attending OPD. In particular, "dysuria" or "scrotum pain or swelling" or presence of a "genital erosion" were reported at least twice as frequently in the community group. The same men also over-reported symptoms not related to STD such as fever and diarrhoea (data not shown). Conversely, STD signs were more frequently observed by clinicians in the OPD group, except for genital ulcers which were twice as prevalent in the community group $(2 \cdot 6 \%$ versus $1 \cdot 3 \%)$. Symptoms and signs were particularly poorly correlated among men in the community. Fifty two of 289 these men complained of dysuria and/or

Table 3 Prevalence of signs and symptoms related to STDs among Rwandan refugees in Tanzania

\begin{tabular}{|c|c|c|c|}
\hline Signs and Symptoms & $\begin{array}{l}\text { Antenatal } \\
(N=100)\end{array}$ & $\begin{array}{c}\text { Male OPD } \\
(N=239)\end{array}$ & $\begin{array}{l}\text { Male community } \\
(N=289)\end{array}$ \\
\hline \multicolumn{4}{|l|}{ Symptoms: } \\
\hline Dysuria & 15 & $20(8 \cdot 4)$ & $43(15)$ \\
\hline Dyspareunia & 17 & - & - \\
\hline Genital discharge & 35 & $6(2 \cdot 5)$ & $10(3 \cdot 4)$ \\
\hline Genital ulcer & 6 & $4(1.7)$ & $10(3.4)$ \\
\hline Lower abdominal pain (LAP) & 56 & - & - \\
\hline Swollen inguinal glands & 0 & $4(1 \cdot 7)$ & $46(16)$ \\
\hline Swollen/pain scrotum & - & $5(2 \cdot 1)$ & $21(7 \cdot 2)$ \\
\hline Skinrash & 0 & $3(1 \cdot 3)$ & $22(7 \cdot 6)$ \\
\hline Any STD symptom & 63 & $29(12)$ & $83(28)$ \\
\hline Received treatment for STD & $11 / 63(17 \%)$ & $10 / 29(35 \%)$ & $19 / 83(23 \%)$ \\
\hline \multicolumn{4}{|l|}{ Signs: } \\
\hline Genital discharge & 51 & $8(3 \cdot 3)$ & $1(0 \cdot 3)$ \\
\hline Genital ulcer & 0 & $3(1 \cdot 3)$ & $7(2 \cdot 3)$ \\
\hline Dysplasia & 4 & - & - \\
\hline Other conditions & 6 & $14(5 \cdot 9)$ & $10(3 \cdot 5)$ \\
\hline
\end{tabular}

urethral discharge, but a discharge was only observed in one.

Only $35 \%$ of the male OPD patients and $23 \%$ of the community males reported seeking treatment for their current STD symptoms. The source of care also differed: $90 \%$ of the

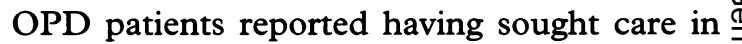
the formal sector, whilst only $47 \%$ of community males attended a hospital, and the majority $(52 \%)$ went to a traditional healer.

Relationship between STD symptoms, signs and confirmed infections

All three women infected with NG were concurrently infected by TV, so that symptoms for each infection could not be separated: in all these cases, women complained of an abnormal discharge, which was confirmed of clinically.

Of the 31 women infected by TV, 20 (65\%) had symptoms, compared with only $20 / 69$ $(29 \%)$ of non-TV infected women. All $31 \stackrel{\text { ? }}{=}$ cases of TV infection were accompanied by $\omega$ visible discharge on examination, whilst only $29 \%(20 / 69)$ of TV-free women had a dis- $\omega$ charge. The discharge in TV infected women 옥 was often purulent (24/31), but more rarely abundant (14/31), frothy (12/31), or malodorous (8/31), which are all "classical" signs of infection by this pathogen. Symptoms were less frequently reported by women with candida infections (in less than $50 \%$ of cases) although all cases had a visible, often abundant and curd-like, discharge on examination.

The positive predictive value of the leucocyte esterase (LE) test for confirmed urethritis (gonorrhoea or NGU) was only $10 \%$ among $\stackrel{\varnothing}{\varnothing}$ male outpatients, and $7 \%$ among men in the $\vec{F}$ community. This is a reflection of the low 3 prevalence of urethritis in these populations, and of the low specificity of the LE test result-

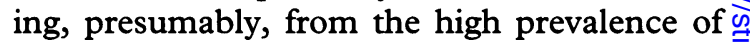
other conditions (eg. schistosomiasis) giving rise to a positive LE test. Unfortunately it was not possible to look for these in this study.

Discussion prevalent in antenatal clinic attenders in this of study, although it is likely that the prevalence $N$ of gonorrhoea was underestimated since we used the relatively insensitive cervical Gram stain, rather than culture, to diagnose it. Theo high prevalence of RTIs found accords with results found in the neighbouring Mwanza? Region, where $49 \%$ of rural ANC attenders had an RTI. " Use of syndromic treatment $\stackrel{\square}{\Phi}$ algorithms represents an opportunity for treat- $\frac{O}{\Phi}$ ing all pathogens causing vaginal discharge, but may result in over-treatment for NG and Chlamydia trachomatis (CT).

Among men in these refugee camps the prevalence of NG was between 1 and $2 \%$ and of urethritis approximately $3 \%$, and the majority of these infections were asymptomatic. These results are similar to those of a survey among men in rural Mwanza Region, in which $77 \%$ of men with NG/CT infection had no symptoms or signs. ${ }^{12}$ The low positive predic- 
tive value of the LED test for urethritis and for NG/CT infection in this refugee population is similar to that found among rural men in Mwanza $^{1213}$; it is likely that many positive LED tests are due to Schistosoma haematobium infection, which is endemic in the region.

There are several possible explanations for the poor correlation between confirmed signs and proven laboratory infections in men: clinicians may have failed to identify some discharges, especially after patients had voided, and some agents causing biological urethritis and urethral symptoms such as CT, TV or other bacteria (such as Mycoplasma spp) were not tested for. The prevalence of current STD symptoms was high, especially in the community males, perhaps due to some expectation for treatment or to some misunderstanding about the symptoms, to psychosomatic disorders (many of these men had suffered severe psychological trauma), or to poor genital hygiene (due to a lack of washing facilities) leading to a high prevalence of non-STD related balanitis.

\section{Future STD control in refugee camps}

The poor positive predictive value of certain symptoms (entry points for syndromic management) may seem an obstacle to effective and rational management. However, it appears that symptoms are more often related to signs for patients who come spontaneously to an OPD. Therefore, reported symptoms from the genital region should be confirmed either by a clinical examination, or by LED testing, and syndromic management applied from that point. The LED test was not a useful screening test for men without urethral symptoms.

Training in syndromic management of STDs is a priority in the refugee camps, and it is important that all service-delivery staff should be aware of the importance of STDs and know how to recognise them. Practical use of STD flowcharts is not difficult to teach, but this is not the only component of proper STD management, which also includes prevention activities such as condom promotion, counselling, and partner notification.

Women should be encouraged by clinic staff to report genital symptoms. Privacy should be ensured in order to perform genital examination, which may not necessarily include speculum, but at least inspection. Aetiological diagnosis by type of discharge is not recommended, except perhaps in the case of candidosis. Every woman complaining of genital discharge syndrome should at least be treated for TV/BV and CA, unless the latter can be excluded by a speculum examination. NG/CT treatment could also be added on both public health grounds (to prevent transmission) and on clinical grounds (to prevent complications); but this would lead to unnecessary treatment for gonorrhoea of many women in this low prevalence population. Alternatively, a risk-score approach for NG/CT treatment could be applied, ${ }^{17}$ but such an approach has not been evaluated in this context. Rapid Plasma Reagin screening is a feasible and cost-effective strategy for the prevention of congenital syphilis in resourcepoor countries with a high prevalence of syphilis, ${ }^{1819}$ and should be introduced in the ANC clinics in the camps.

There is a need for information, education and communication activities to educate the population about the symptoms of STDs and to encourage them to report such symptoms at the health centres for treatment. Education concerning genital hygiene would be beneficial and one cost-effective intervention may be the provision of public "bathrooms" in the camps. This would not only save money for unnecessary treatment of "genital complaints", but would also decrease the level of genital inflammation that may also enhance the transmission or acquisition of HIV infection.

\section{The study methodology}

To our knowledge, a rapid assessment of STDs has only been used once in a refugee crisis in Ethiopia (Sudanese refugees) in 1992-1993. ${ }^{20}$ However, in that survey, the camp population was smaller (about 6,000 ), comprising mostly of males, the camp had been established since 1987, and the survey had a major focus on the neighbouring communities in order to set-up appropriate STD services. The time span for the study was one month. Thus, our study has provided the first opportunity to test the rapid STD assessment methodology on a large scale and in a very short time. Critical review of the methodology is relevant, as this type of assessment may be used elsewhere.

The survey among male OPD attenders and in the community, including multi-stage sampling methods, probably ensured that a representative sample of men was seen and that any bias would be minimised. ${ }^{21}$ There may be some loss of sensitivity when taking swabs for NG after a void urine, due to the washing out of pathogens from the urethra, but this should be small. Moreover, since the sensitivity of the LE test for the detection of urethritis is not known in this population, it is possible that cases were overlooked due to the policy of taking urethral swabs only from LE positive men.

Among many populations in Africa ANC attenders have been taken as representative of the general population of fecund women. This may not be true in the refugee camps where the transitory nature of life may not be conducive to the routine pregnancy checkup. Also there was only one ANC in operation at that time, and access to the clinic was probably restricted to a few women who were more concerned for or aware of their pregnancy. However within these limitations it is difficult to obtain a genuine population sample of women who would be willing to submit to genital examination and sampling.

\section{Conclusion}

Rapid STD assessment can be useful in obtaining quick and reliable information at low cost. Rapid dissemination of survey results ensured that STD control was accorded 
higher priority in the camps, and encouraged AMREF, UNHCR and other NGOs to launch targeted programmes for STD training of health workers and IEC activities. These improved services should restore the confidence of the community in the ability of the health services to cure STDs. The results of this survey provided a basis for case projection and budget planning; a second rapid assessment of STDs will be conducted to evaluate the impact of these changes.

We express our sincere gratitude to the medical coordinators of the various NGOs for their valuable assistance: Medecins Sans Frontières of Spain, Holland, and France, the African Education Fund, the Tanzanian Red Cross, and the Education Fund, the Tanzanian Red Cross, and the Murgwanza Hospital for their generous assistance in providing Murgwanza Hospital for their generous assistance in providing accommodation and permission to use their laboratory facilities. We thank Tanzanian medical authorities at all levels WACP, RMO and DMO) for their support and contribution. and we wish to acknowledge their hard work.

AMREF's Programme in the Rwandan refugee camps is cosponsored by the United Nations Population Fund (UNFPA) and the United Nations High Commission for Refugees (UNHCR). We also gratefully acknowledge the support of the European Communities (DGVIII), the Overseas Development Administration and the Centre for International Migration and Development.

1 Piot P, Laga M. Genital ulcers, other sexually transmitted diseases, and the sexual transmission of HIV. The first two may be important risk factors for the third. $B M \mathcal{F}$ two may be imp

2 Pepin J, Plummer FA, Brunham RD, Piot P, Cameron DW, Ronald AR, et al. The interaction of HIV and other sexually transmitted diseases: an opportunity for intervention. AIDS 1989;3:3-9.

3 Mertens TE, Hayes RJ, Smith PG. Epidemiological methods to study the interaction between human immunodeficiency virus infection and other sexually transmitted diseases. AIDS 1990;4:57-65.

4 Rwanda HIV seroprevalence study group. Nationwide community-based serological survey of HIV-1 and other human retrovirus infections in a central African country. Lancet 1989;i:941-4.

5 Killewo JZ, Sandstrom A, Bredberg-Raden U, Mhalu FS, Biberfeld G, Wall S. Incidence of HIV-1 infection among adults in the Kagera Region of Tanzania. Int $\mathcal{F}$ Epidemiol 1993;22:528-36.

6 Grosskurth H, Mosha F, Todd J, Mwijarubi E, Klokke A,
Senkoro K, et al. Impact of improved treatment of sexually transmitted diseases on HIV infection in rural Tanzania: randomised controlled trial. Lancet 1995;346:530-6.

7 UNHCR Medical Coordination Ngara. Morbidity \& mortality data, Benaco camp, May-July 1994.

8 Porter JDH, Van Loock FL, Devaux A. Evaluation of two Kurdish refugee camps in Iran, May 1991: the value of cluster sampling in producing priorities and policy. Disasters 1993;17:341-7.

9 Roseberry WL, Heymann DL, Ndoye I, Nsubuga P. Rapid sexually transmitted diseases assessment in two developing countries. Sex Trans Dis 1994;21;Suppl 2:S84-S85.

10 Spiegel CA. Bacterial vaginosis. Clin Microb Rev 1991;4: 485-502.

11 Mayaud P, Grosskurth H, Changalucha J, Todd J, West B, Gabone $\mathrm{R}$, et al. Approaches to the identification of gonorrhea and chlamydial infection in rural Tanzania ANC attenders: risk-assessment and other screening options. $\overrightarrow{\vec{F}}$

12 Grosskurth H, Mayaud P, Mosha FF, Tood J, Senkoro K, Newell J, et al. High prevalence of asymptomatic gonorrhea and chlamydial infection in rural Tanzanian men. $B M \mathcal{A}$ 1996; (In press)

13 Mayaud $P$, Changalucha $J$, Grosskurth $H$, ka-Gina $G$, Rugemalila J, Nduba J, et al. The value of urine specimens in screening for male urethritis and its microbial aetiologies in Tanzania. Genitourin Med 1992;68:361-5.

14 McNagny SE, Parker RM, Zenilman JM, Lewis JS. Urinary leucocyte esterase test: a screening method for the detection of asymptomatic chlamydial and gonococ- $\vec{\omega}$ the detection of asymptomatic chlamydial and go

15 Mosha FF, Nicoll A, Barongo L, Borgdorff M, Newell J, क Senkoro $\mathrm{K}$, et al. A population-based study of syphilis and sexually transmitted disease syndromes in North- $\omega$ Western Tanzania. 1. Prevalence and incidence. Genitourin Med 1993;69:415-20.

16 Arya OP, Nsanzumuhire H, Taber SR. Clinical, cultural $\omega$ and demographic aspects of gonorrhoea in a rural com- $O$ munity in Uganda Bull World Health Organ 1973;49. munity

17 Vuylsteke B, Laga $M$, Alary $M$, Gerniers $M-M$, Lebughe T $\mathrm{J}-\mathrm{P}, \mathrm{Nzila} \mathrm{N}$, et al. Clinical algorithms for the screening of women for gonococcal and chlamydial infection: evaluation of pregnant women and prostitutes in Zaire. Clin Inf Dis 1993;17:82-8.

18 World Development Report 1993. Investing in Health. New York: Oxford University Press for the World Bank 1993.

19 Hira SK, Bhat GJ, Chikamata DM, Nkowane B, Tembo . G, Perine PL, et al. Syphilis intervention in pregnancy: Zambian demonstration project. Genitourin Med 1990; 66:159-64.

20 Center for Disease Control and Prevention, Ministry of Health, Ethiopia, and UNHCR-Ethiopia. Progress Report of the STD/HIV Control and Prevention Project, Bench Zone, Region 8 (formerly Keffa Region), Ethiopia, August 1993.

21 Cochran WG in Sampling Techniques. Wiley, New York, 1977:292-311. 